\title{
A Conceptual Framework of Analytical CRM in Big Data Age
}

\author{
Chien-hung Liu \\ Department of Management Information Management \\ National Chengchi University \\ Taipei, Taiwan
}

\begin{abstract}
Traditionally, analytical CRM (A-CRM) mainly relies on the use of structured data from a data warehouse where data are extracted, transformed, loaded from operation systems such as ERP, SCM or operational CRM. In recent years of rising big data trend, recognized shifts in E-commerce have taken place from internet-enable commerce (I-commerce), to mobile commerce (M-commerce), and now to ubiquitous commerce ( $U$ commerce).

As theses paradigm shifts imply that ubiquitous computing improves considerably companies' access to information by allowing them to acquire information at anytime, anywhere. Give this changes on data collection shifts due to ubiquitous computing, however, current A-CRM framework in literature seems not too matched to this change. There is only a handful studies published on CRM in ubiquitous computing environment fitting what big data age requires. Consequently, the objective of this study attempts to propose a conceptual framework of ACRM. Built by conceptual framework approach, this framework provides valuable directions, definitions and guidelines to practitioners preparing the successful big data marketing in big data age.
\end{abstract}

\section{Keywords-CRM; Analytical CRM; Big Data; CRM Framework}

\section{INTRODUCTION}

Traditionally, analytical CRM (A-CRM) mainly takes advantage of the structured data stored in data warehouse, which collects through operation systems such as ERP, SCM or operational CRM, to create knowledge and insights.

Ubiquitous Computing is already more than a mere technology vision. RFID has already reached a high degree of maturity and is entering more application areas [9]. In recent years, recognized shifts in E-commerce have taken place from I-commerce, to M-commerce, and to ubiquitous commerce (Ucommerce) [8]. Kim, Oh and Shin [2] further pointed out that ubiquitous computing improves considerably companies' access to information by allowing them to acquire information at anytime, anywhere.

Give these changes on data collection shifts due to ubiquitous computing, traditional A-CRM frameworks seems not to match up this trend shift. In addition, there are less studies published on CRM in ubiquitous context.

In addition, Ranjan and Bhatnagar [6] believe that traditional operational framework of the customer information has reached its maximum benefit. Likewise, this study believes that the scope of A-CRM should cover different CRM platforms.

Consequently, built on the prior research, the objective of this study aims to propose a conceptual framework of A-CRM with consideration of ubiquitous computing and $\mathrm{U}$-commerce.

This study is organized as follows: (1) introduction ;(2) literature review; (3) research (4) a conceptual framework; and (4) conclusions.

\section{LITERATURE REVIEW}

\section{A. Ubiquitous computing (UbiComp)}

Ubiquitous computing suggests countless very small, wirelessly intercommunicating microprocessors embedded into objects. Equipped with sensors, these computers can record the environment of the objects and provide it with information processing and communication capabilities [9].

Applications of ubiquitous computing are widespread today, for example, retail, personal identification, health care, mobility and transport [9]. In particular, Krumm [5] predicted that ubiquitous advertising will be killer application for the 21 st century.

\section{B. U-commerce}

Watson, Pitt, Berthon and Zinkhan [13] coined the term "U-commerce" and defined it to as

"the use of ubiquitous networks to support personalized and uninterrupted communications and transactions between a firm and its various stakeholders to provide a level of value, above and beyond traditional commerce."

$\mathrm{Wu}$ and Nisa [8] indicated two important traits for Ucommerce: ubiquity and universality. "Ubiquity" means that systems can support a rich set of computing and communication capabilities and services while "Universality" means that these systems provide a universal service channel that enables users to stay connected anywhere, anytime, using any devices [8].

In I-commerce stage, internet allows customers to conduct commerce without physical restriction. M-commerce relaxes the independent and mutual constraints of space and time for many commercial activities [13], adding more values then Icommerce. With respect to U-commerce, because it is considered an integration of different channels (from Internet to brick-and-mortar stores), a diversity of ways in which 
content and services are processed and transmitted [8]. And thus U-commence provides more values then $\mathrm{M}$-commerce and traditional i-commerce.

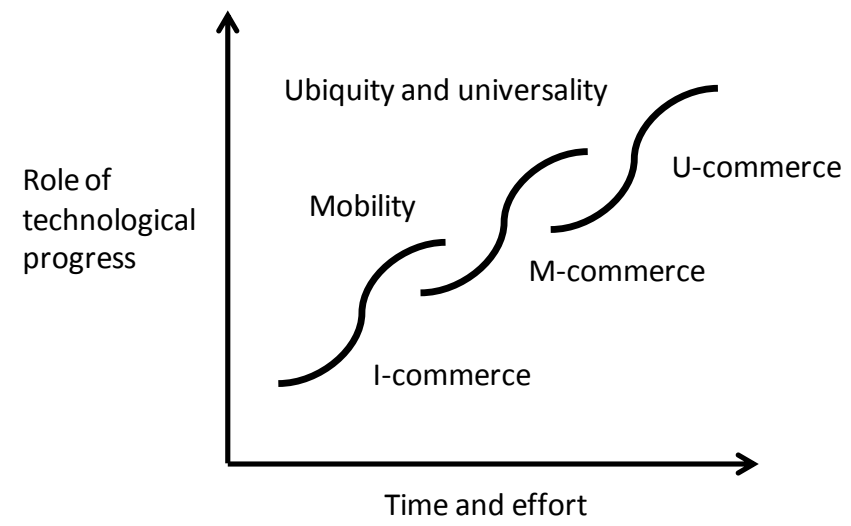

Fig. 1. S CURVES OF EC INNOVATION FROM I-, M-, TO U-COMMERCE [8]

\section{Customer Relationship Management}

In past years, the definition of CRM was not universally agreed among scholars or practitioners. Through years of discussion, definitions for CRM, become more clear. Buttle [4] defines four types of CRM that are mainly used today, depending on the roles that CRM play (Table 1).

TABLE I. TYPE OF CRM [4]

\begin{tabular}{|l|l|}
\hline $\begin{array}{l}\text { Type of } \\
\text { CRM }\end{array}$ & Dominant Characteristic \\
\hline Strategic & $\begin{array}{l}\text { Strategic CRM is a core customer-centric business strategy } \\
\text { that aims at winning and keeping profitable customers }\end{array}$ \\
\hline Operational & $\begin{array}{l}\text { Operational CRM focuses on the automation of customer- } \\
\text { facing process such as selling, marketing, and customer } \\
\text { service }\end{array}$ \\
\hline Analytical & $\begin{array}{l}\text { Analytical CRM focus on the intelligent mining of customer- } \\
\text { related data for strategic or tactical purposes }\end{array}$ \\
\hline Collaborative & $\begin{array}{l}\text { Collaborative CRM applied technology across organizational } \\
\text { boundaries with a view to optimizing company, partner and } \\
\text { customer value }\end{array}$ \\
\hline
\end{tabular}

\section{RESEARCH METHODOLGY}

This study integrated a synthesis of the literature across several academic declines such as Information System (IS), Marketing, Strategy and emerging areas such as big data and ubiquitous commerce to develop a conceptual framework.

This study also use qualitative method interviews with 5 marketing leaders and CRM practitioners from Taiwan to explore and validate how experts think with the proposed framework. These experts that are familiar with CRM were invited to participate. The interviews, ranged from 1 to 2 hours, were conducted during December in 2014. For confidentiality, the name of companies and participants will be presented anonymously.

\section{A CONCEPTUAL FRAMEWORK}

This study has developed a conceptual framework for ACRM with consideration of ubiquitous computing in order to provide with a complete picture of A-CRM.

\section{A. Loyalty Scheme}

Many scholars tend to view loyalty scheme as a reward program for repeated customers [1][3][4].

This study takes definitions from Liu [1] that a loyalty scheme is a scheme that collects customer information and purchase behaviors, leverages IS technologies to customize rewards for repeated customers so as to develop their long-term profitable loyalty.

The analytical framework starts with customer data collection through loyalty schemes, regarding its forms, virtual or physical. Loyalty schemes can help business to acquire customers and their customer data, which includes demographics profile, contact information and customer permission of use these data. Therefore, from an analytics point of view, loyalty scheme plays a key role in collecting customer information, which paves the way for CRM and later target marketing.

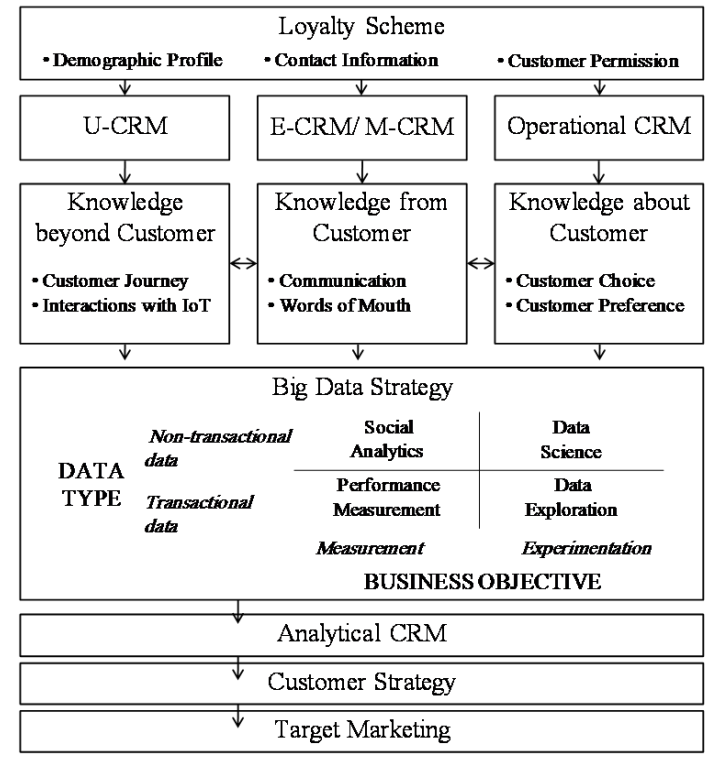

Fig. 2. A CONCEPTUAL CRM FRAMEWORK $\square$

\section{B. Operational CRM (O-CRM)}

Most of structured data for a conceptual CRM Framework business are collected from Operational CRM (O-CRM) with diverse sources. For example, ERP, SCM, marketing CRM, Sales CRM, call center CRM or etc provide business with knowledge about customers through the transacted data. For example, customer choice and preference can be analyzed through or purchase history associate with customers. In this study, O-CRM, refers to any traditional information systems (IS) that automate customer-facing processes that support selling, marketing and customers services.

\section{Electronic CRM (E-CRM) \& Mobile CRM (M-CRM)}

E-CRM is any CRM system that is internet-based. Comparing with traditional O-CRM, E-CRM can supplement O-CRM with non-transactional data in addition to structured data. Data from customers can transactional data through internet or customer communication and interaction data, or even customers' words on the internet. 
Mobile CRM is an information system (IS) extending CRM capabilities beyond internet-based platform to mobile devices, which, with its nature of mobility, can collect information from customers, such with location-based, or time-based data and can interact with customers in a real-times manner.

\section{Ubiquitous CRM (U-CRM)}

$\mathrm{Wu}$ and Nisa [8] argue that, in recent years, recognized shifts in E-commerce have taken place from I-commerce, to M-commerce, and to ubiquitous commerce (U-commerce) by the development of ubiquitous computing.

Atapattu and Sedera [11] define U-CRM as the use of Ubiquitous Retailing (UR) for their customer relationship management, by retailers specifically. However, ubiquitous technologies are not limited to retail only. For example, Friedewald and Raabe [10] identified other areas of application of ubiquitous computing includes industrial production and management, transport logistics, personal identification and authentication, heath care, mobility and transport.

Therefore, this study terms ubiquitous-CRM (U-CRM) as a CRM system supported by ubiquitous technologies that can sense customer needs and wants, engage customers and used for building long term profitable relationship.

Traditional O-CRM means any information system (IS) that automate the customer-face process that support selling, marketing and customer service. By definitions of Buttle [4], U-CRM, Mobile-CRM, and E-CRM all fill into O-CRM category except the technological platforms based are different.

\section{E. Big Data Strategy}

Traditional O-CRM provides most of structured data, such as customer transactions, customer choices of products while E-CRM, Mobile CRM and ubiquitous CRM (U-CRM) bring additional new information from customers such as data collected during social communications and interactions, mobility, or customers' word-of-mouth and sentiments, communications between humans, or even devices between devices. This type of data are often heterogeneous and diverse (verity), produced in a real-time fashion (velocity) and big (volume). These three characteristics fit the nature of "big data" described by Doug Laney [9].

Parise, Iyer and Vesset [14] proposed a big data framework for business to shape up strategies to capture and create value. Based on the data type (Y-axis) and business objective (Xaxis), a 2x2 matrices is formulated. Big data strategy will provide business with four strategies for value creation from big data, which also can guide the A-CRM.

\section{F. Analytical CRM (A-CRM)}

Buttle [4] indicates that A-CRM focus on intelligently mining customer-related data for strategical or tactical purposes. Peppers and Rogers [3] thinks A-CRM focuses on the strategic planning needed to build customer value as well as cultural, measurement, and organizational changes required to implement that strategy successfully. Thus, this study believes that A-CRM helps create customer strategy (strategical purpose) that guide target marketing (tactical purpose).
In the U-commerce context, ubiquitous networking is used; The development system is seamlessly integrated with other system; Content design provides needed-based information; , delivery is seamless; services is omnipresent; transactions are multi-disciplined, virtual or physical,; and payment system are diverse [8].

These critical differences imply that business has more opportunity than ever to collect from customers anywhere, anytime, from any devices. This means A-CRM will acquire new data about customer journey, and their communications with other IoT device from U-CRM.

\section{G. Customer Strategy}

Customer strategies involves examining the existing and potential customer based and identify which forms of segment are most appropriate [12]. This study believes whether a macro, micro, or one-to-tone segmentation approach is appropriate is a decision for a business to make.

\section{H. Target Marketing}

Targeted marketing is a process where segmentation, targeting, and positioning have to be linked [12]. Peppers and Rogers [3] proposed a "Enterprise Strategy Map" that formulates four strategies based on the level of interacting with individual and level of tailoring products.

At level of granularity of target marketing, one-on-one learning relationship is a cost-efficient target marketing strategy. One-on-one means everyone can be accurately identified, reached with offers or products that are tailored made for each single one of customers. Learning relationship means the data collection through interactions between customers and company as a learning relationship [3]. An increasing number of marketers are looking at personalization to help improve their marketing and expect to bring benefits of one-to-one marketing and customer-relationship management [7].

\begin{tabular}{ll|c|c}
\multirow{2}{*}{ Interacting } & $\begin{array}{l}\text { Ability to interact with } \\
\text { customer individually }\end{array}$ & $\begin{array}{c}\text { Database } \\
\text { marketing }\end{array}$ & $\begin{array}{c}1-1 \text { learning } \\
\text { relationship }\end{array}$ \\
\cline { 3 - 4 } $\begin{array}{l}\text { Customers addressed } \\
\text { only in mass medias }\end{array}$ & $\begin{array}{c}\text { Mass } \\
\text { marketing }\end{array}$ & $\begin{array}{c}\text { Niche } \\
\text { marketing }\end{array}$ \\
\cline { 3 - 4 } & \multicolumn{2}{c}{$\begin{array}{l}\text { Standard } \\
\text { products }\end{array}$} & $\begin{array}{l}\text { Tailored } \\
\text { products }\end{array}$
\end{tabular}

Fig. 3. Enterprise Strategy Map [3]

\section{CONCLUSIONS}

Ubiquitous Computing is already more than a mere technology vision. RFID has already reached a high degree of maturity and is entering more application areas [9]. In the ubiquitous age, each individual can be interacted and offered unique tailored product Anywhere, Anytime, with Any device And thus ubiquitous commerce technologies can help customers to get a completely tailored experience with context

This study contributes a conceptual framework for analytical CRM that considers big data happened at a ubiquitous computing environment, which can guide the practitioners or marketers prepare for big data marketing. 
This conceptual framework is developed based on combining previous literature, experience as expert opinions. However, this study is not without its limitation. Give a tremendous of own expertise and experience has been devoted to this study, future researcher should consider to include a field-based validation to make this framework more robust and practical as it aims to.

\section{REFERENCES}

[1] C. H. Liu, "A proposal of a typology of loyalty scheme," A paper accepted by Technology Innovation and Industry Management (TIIM) 2014 Conference, May 28-30, South Korea.

[2] C. Kim, E. Oh and N. Shin, "An empirical investigation of factors affecting ubiquitous computing use of U-business value," International Journal of Information Management, vol 28, pp. 436-448, 2011.

[3] D. Peppers and M. Rogers, "Managing customer relationship- a strategic framework," John Wiley \& Sons, Inc. Hoboken, NJ, USA, 2011

[4] F. Buttle, "Customer Relationship Management- Concepts and Technologies", Butterworth-Heinemann, Burlington, MA, USA, 2009

[5] J. Krumm, "Ubiquitous Advertising: The Killer Application for the 21st Century," IEEE Pervasive Computing, 10(1), 66-73, 2011.

[6] J. Ranjan and V. Bhatnagar, "Role of Knowledge Management and Analytical CRM in Business: Data Mining Based Framework," The Learning Organization, vol. 18, pp. 131-148, 2011.
[7] J. Versanen and M. Raulas, Building Bridges For Personalization: A process Model for Marketing. Journal of Interactive Marketing, vol. 20, 2006

[8] J. Wu and T. Hisa, "Developing E-business Dynamic Capabilities: An Analysis of E-commerce Innovation From I-, M-, to U-commerce," Journal of Organizational Computing and Electronic Commerce, vol.18, pp. 95-111, 2008

[9] L. Doug, "3D Data Management- Controlling Data Volume, Velocity, and Varity," Application Delivery Strategy, META Group, February, 2001

[10] M. Friedewald and O. Raabe, "Ubiquitous computing: An overview of technology impacts," Telematics and Information, vol 29, pp. 55-65, 2009.

[11] M. Atapattu and D. Sedera, "Ubiquitous Customer Relationship Management: Unforeseen Issues And Benefits," Pacific Asia Conference on Information Systems (PACIS), 2012

[12] P. Frow and A. Payne, "Customer Relationship Management: A Strategic Perspective," Journal of Business Market Management, Vol. 3, 7-27, 2009.

[13] R. T. Watson, L. F. Pitt, P. Berthon and G. M. Zinkhan, "U-commerce: Extending the universe of marketing," Journal of the Academy of Marketing Science, vol. 30, pp. 329-343, 2002.

[14] S. Parise, B. Iyer and D. Vesset, "Four Strategies to Capture and Create Value from Big Data," Ivey Business Journal, University of Toronto, July/August, 2012. 